Pesquisa e Reflexão em Educação Básica

\title{
Tematização da Cultura Corporal Africana e Afro-Brasileira na Educação Física: uma experiência de estágio na Educação Infantil
}

\author{
Pedro de Oliveira Milagres* \\ Anderson da Cunha Baia** \\ Doiara Silva dos Santos ${ }^{* * *}$
}

\section{Resumo:}

A Cultura Corporal consiste em um conjunto de conhecimentos tratados pela Educação Física que reconhecem as expressões corporais enquanto linguagens histórica e culturalmente construídas, sendo a africana e afro-brasileira próprias em suas especificidades no que tange ao corpo e às práticas corporais. Este trabalho tem como objetivo apresentar e discutir a tematização da cultura corporal africana e afro-brasileira na Educação Infantil, orientada por uma proposta crítica de ensino, a partir da experiência no estágio supervisionado em Educação Física. Assim, ele consiste em um relato descritivo-reflexivo elaborado por um estagiário, com contribuições dos professores-supervisores, revelando o exercício de planejamento e construção das práticas no contexto escolar. Consideramos que a elaboração do planejamento sob prisma histórico e a sequência didático-pedagógica desenvolvida contribuíram para o processo de ensino-aprendizagem e apropriação da temática por crianças daquele nível de ensino. Além disso, a tematização africana e afro-brasileira permitiu às crianças compreenderem as práticas corporais cotidianas enquanto não-neutras e marcadas pelos saberes de matriz africana.

\section{Palavras-chave:}

Cultura Corporal Africana. Cultura Corporal Afro-Brasileira. Educação Infantil.

\footnotetext{
* Licenciado em Educação Física e aluno no Programa de Pós-Graduação em Educação na Universidade Federal de Viçosa. E-mail: pedromilagres.ef@outlook.com. ORCID iD: http://orcid.org/0000-0002-2178-5279.

** Doutor em Educação, professor do Departamento de Educação Física e da Pós-Graduação em Educação na Universidade Federal de Viçosa. E-mail: andersonbaia@ufv.br. ORCID iD: https://orcid.org/0000-0002-7363-689X.

*** Doutora em Educação Física, professora do Departamento de Educação Física na Universidade Federal de Viçosa. E-mail: santosdoiara@ufv.br. ORCID iD: http://orcid.org/0000-0002-4718-7226.
} 


\begin{abstract}
:
The body culture consists of an amount of historical and culture knowledge about body expressions, acknowledged as historical and cultural language which are socially buil and congregate their own specificities related to the body and its practices. This experience report aims to present and discuss a critical teaching of the topic african and afro-brazilian body culture with Early Childhood Education, which comes from a supervised internship of undergraduate Physical Education. For that, it provides a descriptive-reflexive report by the intern, with the collaboration of supervisors, unraveling the planning and teaching exercises within the school context. It was concluded that the historical planning and the didactic-pedagogical organization contributed for a teaching-learning process and appropriation of the topics by the children. Also, the topic african and afro-Brazilian body culture allowed children to understand daily practices as non-neutral and marked by African's knowledge.
\end{abstract}

\title{
Keywords:
}

African body culture. Afro-brazilian body culture. Early Childhood Education.

\section{Introdução}

O presente relato tem como finalidade apresentar e discutir a tematização da Cultura Corporal Africana e Afro-Brasileira, orientadas por uma proposta crítica de ensino na Educação Física, realizada durante uma experiência de estágio na Educação Infantil.

Trata-se, portanto, de reflexões aqui escritas por um estagiário, com contribuições dos professores-supervisores, no cumprimento do Estágio Supervisionado (ES), em dupla. As intervenções ocorreram com uma turma de pré-escolares contendo 19 crianças, num Centro Municipal de Ensino ${ }^{1}$ onde comumente ocorrem os estágios em Educação Infantil do curso de Licenciatura em Educação Física de uma universidade pública em Minas Gerais.

O ensino voltado para cultura africana e afro-brasileira, promovido durante o ES, inspirou-se na defesa da ampliação da Lei $n^{\circ} 10.639 / 03^{2}$, em voga nos debates nacionais e apropriados por movimentos negros presentes no contexto da Universidade Federal de Viçosa e em outras instituições ${ }^{3}$. Apesar desta lei estabelecer o ensino dos conhecimentos de matriz africana apenas nos níveis do Ensino Fundamental e Médio, sua concepção na Educação Infantil foi pensada como forma de introduzir os conhecimentos de África na formação, que contribuem para a construção identitária das crianças envolvidas ou, como Climaco, Santos e Taffarel (2018) afirmam, para a possibilidade de humanizar o ser humano no ensino da Educação Física.

As intervenções se iniciaram com a elaboração de um planejamento abordando a Cultura Corporal ligada à matriz africana, dando ênfase ao contexto histórico-cultural. Entende-se por Cultura Corporal o conjunto de conhecimentos tratados pela Educação Física que reconhecem as expressões corporais enquanto linguagens histórica e culturalmente construídas (SOARES, et al., 1992). Assim, convencionou-se denominar o conjunto de conhecimentos trabalhados ao decorrer da disciplina de ES enquanto Cultura

\footnotetext{
1. A escola na qual ocorreram as aulas é uma instituição pública municipal, localizada no espaço urbano, e atende alunos da Educação Infantil e Ensino Fundamental. Com relação a infraestrutura, a escola possuía espaços abertos destinados às aulas de Educação Física, como um parquinho, dois pátios e um espaço de corredor. Havia, também, uma quadra poliesportiva coberta, recém construída, contudo a escola ainda não possuía autorização para uso.

2. A Lei no 10.639/03 pauta a discussão da cultura e história africana e afro-brasileira nas ações educacionais presentes no cotidiano escolar. Nela se prevê o estudo "da História da África e dos Africanos, a luta dos negros no Brasil, a cultura negra brasileira e o negro na formação da sociedade nacional, resgatando a contribuição do povo negro nas áreas social, econômica e política pertinentes à História do Brasil" (BRASIL, 2003).

3. A principal inspiração veio do Núcleo de Estudos Afro-Brasileiros de Viçosa (NEAB-Viçosa) e de outros NEABs vinculados a instituições de Ensino Superior.
} 
Corporal Africana e Afro-Brasileira. Enquanto a primeira diz respeito ao conjunto de expressões corporais construídos em África, a segunda situa práticas corporais praticadas no Brasil que foram reproduzidas, ressignificas ou inspiradas em práticas de matriz africana.

Com enfoque na construção de práticas da Educação Física que contribuam com um projeto de formação às crianças e passíveis à articulação de diferentes saberes, nos inspiramos na abordagem crítico-superadora. Segundo Soares et al. (1992), a pedagogia crítico-superadora se funda enquanto uma pedagogia que visa corresponder a determinados interesses de classe, especialmente a classe trabalhadora, portanto, em busca de justiça social em sentido teleológico. Construir práticas na Educação Física a partir da lógica da Cultura Corporal não se encerra em objetivos próprios à área, uma vez que, "assinalar à disciplina Educação Física o campo da Cultura Corporal como objeto de estudo não significa perder de vista os objetivos relacionados com a formação corporal, física, dos alunos, senão, recolocá-los no âmbito espaço-temporal da vida real de uma sociedade de classes" (TAFFAREL, 2016, p. 10).

Sistematizar uma lógica de Cultura Corporal Africana imbricando-a na Cultura Corporal Afro-Brasileira significa demarcar, junto aos alunos, a influência dos saberes da África nos conteúdos da Educação Física. Nessa experiência de estágio, especificamente, os conteúdos eleitos para a sequência de intervenções foram os "jogos e brincadeiras".

Portanto, esse relato apresenta reflexões das experiências no cumprimento do es com a tematização da Cultura Corporal Africana e Afro-Brasileira, por meio do conteúdo "jogos e brincadeiras". Para isso, buscamos representar o processo de construção do planejamento e realização das aulas, dando destaque à articulação da proposta com o nível de ensino.

\section{Planejamento e construção das práticas}

Na perspectiva do estagiário, o ES na Educação Infantil foi permeado por um conjunto de inseguranças prévias quanto ao trabalho com crianças. Fatores como o sentimento de falta de preparo técnico para o ensino, o desconhecimento da cultura infantil e o medo de atuação nas aulas produziam esta insegurança. Esse processo foi acentuado pela escolha em tematizar práticas africanas e suas marcas no Brasil, uma vez que referenciais como Pinto, Macamo e Azevedo (2014) sinalizam a pouca atenção dada ou quase inexistência às/das práticas corporais afro-brasileiras e africanas na Educação Física escolar ou nos cursos da área.

$\mathrm{Na}$ construção do planejamento, para além dos saberes curriculares e orientações, a participação em movimentos sociais, experiências cotidianas, leituras e debates em eventos acadêmicos contribuíram para a atuação ${ }^{4}$. Estas experiências ensejaram o interesse em trabalhar a Cultura Corporal Africana e Afro-Brasileira a partir do conteúdo "jogos e brincadeiras".

Tal sistematização foi amparada por alguns documentos legais, como a Base Nacional Comum Curricular (BRASIL, 2017b) que prevê "jogos e brincadeiras" enquanto uma das unidades temáticas a serem ensinadas na Educação Física escolar, a Lei no 10.639 (BRASIL, 2003), com atenção à presença dos sujeitos negros e negras na construção nacional, e a Lei de Diretrizes e Bases da Educação Nacional (BRASIL, 2017), em seu artigo 26, que reconhece a cultura e etnia de matriz africana na formação do povo brasileiro (BRASIL, 2017a). Do ponto de vista institucional, alinhou-se o planejamento ao Projeto Político Pedagógico (PPP) da escola, que afirmava ter o compromisso de superar a "estrutura tradicional dos conteúdos e formas de trabalho, com relação a aprendizagem do aluno, e avançar na construção de uma escola que priorize o crescimento integral e completo do ser humano, levando em conta a aprendizagem" (CMEDJAF, 2017, p. 18).

4. A minha vivência no espaço universitário como estagiário, enquanto um sujeito negro, me levou a participar das reuniões do NEAB-Viçosa onde eram realizados debates em torno de artigos e troca de experiências, a participação no I Encontro de Estudantes e Coletivos Universitários Negros, e aproximação de pesquisas e pesquisadores que abordaram as temáticas étnico-raciais no XX Congresso Brasileiro de Ciências do Esporte. 
Cumprindo o ensino previsto no PPP da escola e os documentos balizadores, foi sistematizado um planejamento sequencial de seis aulas ${ }^{5}$, abordando as relações culturais de dominação e resistência. Como vemos no Quadro 1, em um primeiro momento foi trabalhado o contexto da África e a Cultura Corporal Africana (aulas 1 a 4) e, em um segundo momento, foi trabalhado a exploração dos saberes culturais e as marcas presentes na cultura infantil (aulas 5 e 6 ).

Quadro 1 - Síntese do cronograma de aulas do plano de ensino elaborado

\begin{tabular}{|l|l|l|l|}
\hline Aula & Tema da aula & Objetivo & Resumo da Aula \\
\hline 1 & $\begin{array}{l}\text { Práticas } \\
\text { corporais e } \\
\text { trabalho }\end{array}$ & $\begin{array}{l}\text { Construir conhecimento } \\
\text { acerca de África, a noção de } \\
\text { tribo e práticas corporais } \\
\text { ligadas ao trabalho. }\end{array}$ & $\begin{array}{l}\text { Caracterização inicial de parte da cultura africana por } \\
\text { meio do filme "Kirikou: animais selvagens" (2005), } \\
\text { elementos e práticas corporais ligados a subsistência. }\end{array}$ \\
\hline 2 & $\begin{array}{l}\text { Produção de } \\
\text { brinquedos e } \\
\text { brincadeiras }\end{array}$ & $\begin{array}{l}\text { Produzir brinquedos } \\
\text { a partir de elementos } \\
\text { naturais. }\end{array}$ & $\begin{array}{l}\text { Discussão sobre a brincadeira no cotidiano do Kirikou. } \\
\text { Produção de brinquedos e brincadeiras com argila. } \\
\text { Reflexão sobre a diversão e poder aquisitivo. }\end{array}$ \\
\hline 3 & $\begin{array}{l}\text { Linguagem } \\
\text { pela dança }\end{array}$ & $\begin{array}{l}\text { Compreender rituais corpo- } \\
\text { rais típicos. }\end{array}$ & $\begin{array}{l}\text { Vivência de rituais religiosos de dança. Discussão sobre } \\
\text { os movimentos corporais como comunicação. }\end{array}$ \\
\hline 4 & $\begin{array}{l}\text { Jogos } \\
\text { africanos }\end{array}$ & $\begin{array}{l}\text { Conhecer e vivenciar jogos } \\
\text { e brincadeiras típicos da } \\
\text { Cultura Corporal Africana. }\end{array}$ & $\begin{array}{l}\text { Experimentação de diversos jogos de origem africana. } \\
\text { Explicação da diversidade cultural na África. Expli- } \\
\text { cação sobre a tradição e como ela mantém os jogos } \\
\text { "vivos". }\end{array}$ \\
\hline 5 & $\begin{array}{l}\text { Brinquedo } \\
\text { cantado } \\
\text { "Escravos de } \\
\text { Jó" }\end{array}$ & $\begin{array}{l}\text { Compreender a chegada de } \\
\text { povos africanos no Brasil } \\
\text { por meio de um brinquedo } \\
\text { cantado. }\end{array}$ & $\begin{array}{l}\text { Prática de brincadeiras que retratam relações de } \\
\text { exploração e resistência no período da escravidão no } \\
\text { Brasil. Prática do brinquedo cantado "Escravos de Jó", e } \\
\text { explicação da letra a partir das brincadeiras. }\end{array}$ \\
\hline 6 & $\begin{array}{l}\text { Influência } \\
\text { na África } \\
\text { Corporal } \\
\text { Brasileira }\end{array}$ & $\begin{array}{l}\text { Problematizar as influên- } \\
\text { cias africanas nas práticas } \\
\text { corporais populares no } \\
\text { Brasil. }\end{array}$ & $\begin{array}{l}\text { Vivência de jogos africanos e demonstração das } \\
\text { crianças de brincadeiras similares já vivenciadas. Expli- } \\
\text { cação sobre a importância dos negros para criação de } \\
\text { brincadeiras tradicionais no Brasil. }\end{array}$ \\
\hline
\end{tabular}

Fonte: Elaborado pelos autores.

Ao perspectivar a Educação enquanto ferramenta de transformação dos sujeitos, houve a preocupação em demarcar um afastamento do ensino técnico-biológico em detrimento da aproximação com a pedagogia crítico-superadora. Esperava-se, por meio da Educação Física, permitir aos alunos se compreenderem enquanto sujeitos históricos, capazes de atuar na construção da sociedade e de sua Cultura Corporal (SOARES et al., 1992). A estrutura básica das aulas fez-se em torno de cinco etapas: Prática Social inicial; Problematização; Instrumentalização; Catarse, e; Prática Social final ${ }^{6}$ (SAVIANI, 1991). Tal organização contempla o papel mediador da Educação no processo de transformação social, respeita as individualidades, a interação com os alunos e possibilita a construção do conhecimento a partir da intervenção docente, sendo esta, a base para a pedagogia crítico-superadora definida por Soares et al. (1992). Além disso, tomou-se como princípio norteador dos planos de aula os diferentes saberes - atitudinais, procedimentais e conceituais.

\footnotetext{
5. O ES na Educação Infantil era composto por uma visita técnica, duas observações de aulas e seis intervenções. As aulas ocorriam duas vezes por semana e tinham duração de 50 minutos.

6. Prática social inicial: momento de compreensão da visão do educando acerca do tema e seus conhecimentos prévios; Problematização: confrontação dos conhecimentos iniciais e o conhecimento teórico; Instrumentalização: fase de apropriação do conhecimento através das atividades programadas; Catarse: expressão da nova forma de entendimento, e a ascensão do pensamento através de um debate. Prática Social final: retomada a prática social inicial, agora compreendida como qualitativamente superior à forma pela qual se iniciou a aula. (SAVIANI, 1991).
} 
Durante o planejamento, foi realizado busca e agrupamento de materiais online que pudessem contribuir com as temáticas elencadas, e nesse momento tive contato com o filme Kirikou: animais selvagens (2005). Essa produção narra um conjunto de lendas de África Ocidental, e tem como protagonista Kirikou, que é uma criança da aldeia. São temáticas abordadas nessa produção: os meios de subsistência pela agricultura e manufatura da tribo, a cultura local, a feitiçaria e a relação da tribo com a cidade e a natureza. No que tange à Educação Física, o filme nos traz elementos para pensar o trabalho, a nudez e os rituais corporais, como a dança.

Para as aulas foram selecionados trechos do filme com a finalidade de construir a noção de sujeitos no contexto de símbolos culturais da África que foram capturados e explorados, trazendo sua cultura para o Brasil. Na primeira aula, por exemplo, utilizou-se de um trecho da animação para apresentar a proposta de ensino. A ideia central foi captar suas percepções do continente africano, e utilizar uma variação da brincadeira pique-cola para construir a ideia de coexistência entre a tribo de Kirikou e a natureza. Após este momento conversamos sobre a relação entre tribo/natureza e natureza/cidade, mostrando que ambas relações constituem o território do continente. Este foi um momento de descoberta e surpresa ao perceber que as crianças tinham muito a contribuir para a proposta, pois, naquele momento, não se esperava que as crianças pudessem relacionar os elementos trabalhados na aula com suas experiências cotidianas. Por exemplo, algumas crianças associavam práticas de trabalho agrícola com exercícios presentes em suas casas, sugerindo alguma relação entre elas.

Como a proposta da primeira aula era caracterizar o território do continente africano, foram utilizados elementos imaginários na fala para situá-lo enquanto um continente distante e diverso. Foram trabalhadas, também, noções de culturas e lugares diferentes, bem como a formação de grupos e suas formas de organização social. Questões vindas dos alunos que transpunham o planejado, como a nudez e estigmas acerca de práticas rudimentares, foram utilizadas para reorientar os planejamentos posteriores.

A escolha de trechos do filme Kirikou: animais selvagens que, a princípio, iria inspirar apenas momentos pontuais, tomou grandes proporções e se tornou o insight para as tematizações das aulas que sucederam. O filme alimentava a base do conhecimento acerca do continente africano e os personagens centrais - Kirikou, a mãe e o avô - se tornaram objetos de representação nas brincadeiras, para que os alunos materializassem seu aprendizado. Além disso, devido ao envolvimento dos alunos com a temática, optou-se como estratégia o investimento na construção de materiais em todas as aulas, afim de possibilitar maior autoria e imersão das crianças no processo. Esta estratégia estava diretamente ligada às proposições da abordagem crítico-superadora, que preconiza a importância de se atribuir aos alunos o papel de produtor das práticas corporais, instigando-os em suas capacidades lúdicas e criativas (SOARES et al., 1992).

Logo, na segunda aula, as crianças realizaram a produção de brinquedos através de massinha de modelar, que representavam argila, e criaram brinquedos e formas de brincar com a mesma, em alusão ao enredo do filme. Cumprindo papel de mediador, foram problematizadas diferentes formas de brincar e a possibilidade de se produzir recreação com recursos materiais diversos, por meio de questões como: "Quais brincadeiras as crianças produziam em casa por meio de objetos?"; “Como se adquire um brinquedo?"; "É possível se divertir sem brinquedos prontos ou independente de recursos materiais?”. Assim, retomando a noção de organização social e diferenciação cultural, levantadas na aula anterior, a produção e significação das brincadeiras foi particularizada na experiência com a massinha/argila. A terceira aula, por sua vez, demarcou a especificidade dos símbolos culturais ligados à movimentação corporal, sendo que foi trabalhado a dança e a expressão corporal como formas de agradecimento. Após esta aula foi dado prosseguimento apenas com as representações criadas dos personagens e do contexto.

Por meio da avaliação diagnóstica e formativa foi possível compreender, na quarta e quinta aula, a superação dos conhecimentos iniciais identificados nas primeiras intervenções e a manifestação de conhecimentos mais elaborados, em momentos de conversas e expressões durante a realização das atividades e ao 
final de cada aula. Na quarta aula, foram ensinadas brincadeiras tradicionais de diferentes países de África ${ }^{7}$, junto com seus respectivos nomes, além de trabalhado a noção de práticas conservadas entre as gerações. Foi perceptível que a todo momento as crianças expressavam o nome da brincadeira com a pronúncia na língua local, compreendendo o seu significado. Além do mais, quando foi explicado sobre o que era tradicional e como as brincadeiras passam de geração para geração, uma criança expressou: "Eu vou ter um irmãozinho, e quando ele nascer vou ensinar as brincadeiras que eu aprendi e depois ele vai ensinar para outra pessoa".

Dentro do processo histórico construído, a quinta aula representava o processo de escravização e apropriação da cultura da tribo de Kirikou. Foi construído com os alunos a ideia de que muitas pessoas que, como aquele personagem, moravam no continente de África com suas famílias foram trazidas, com violência, para trabalhar no Brasil. Para problematizar esse processo foi utilizada a cantiga "Escravos de Jó" em três partes: uma brincadeira construindo a primeira parte da letra, em uma noção de exploração; uma segunda brincadeira com a segunda parte da letra, construindo a noção de resistência; e, por fim, a vivência do brinquedo cantado e a história de luta que ele nos conta.

Cada brincadeira era apresentada e explicada, as crianças brincavam e depois era promovido um diálogo de caráter atitudinal. A primeira brincadeira era um caça caranguejo onde me caracterizei enquanto senhor do engenho e exigia, de forma autoritária, que as crianças, enquanto escravos, procurassem os caranguejos escondidos. Ao final foi situado que aqueles caranguejos no cesto eram produto do trabalho dos escravos, mas, foi apropriado pelo senhor e eles não tinham direito de comer. Já na segunda atividade, os alunos precisavam fugir de um quilombo para o outro sem serem pegos pelos capitães do mato. Veja no esquema abaixo:

Escravos de Jó, jogavam caxangá. Tira, bota, deixa o Zambelê ficar...

Guerreiros com guerreiros fazem zigue, zigue, zá! Guerreiros com guerreiros fazem zigue, zigue, zá!

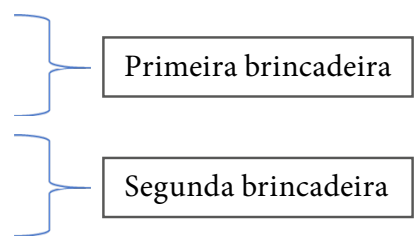

Por fim, embasado na ideia de uma chegada e apropriação dos costumes de Kirikou e sua família, na última aula foram experienciadas brincadeiras tipicamente africanas e brincadeiras conhecidas no Brasil, mostrando que a última se apropriou da primeira. A avaliação foi processual, ao decorrer de toda a aula, onde se buscou observar a capacidade das crianças de enxergarem que nossas brincadeiras tinham marcas africanas. As crianças, de modo geral, demonstravam conhecimento das brincadeiras e, na Prática Social final desta aula, apontaram, coletivamente, brincadeiras que já participaram e são similares às visualizadas nas três últimas aulas. Apesar dos contratempos que acometiam as intervenções, como atrasos para chegada com as crianças no espaço de aula e problemas na organização das atividades, considera-se que houve o aproveitamento e apropriação da temática por parte das crianças.

\section{Cultura Corporal Africana e Afro-Brasileira: desafios e possibilidades}

A inclusão de saberes de matriz cultural africana - muitas vezes desconsideradas nos currículos de Educação Física escolar - logo no primeiro estágio e na Educação Infantil, foi desafiador e ao mesmo tempo gratificante. Várias inseguranças que permearam a construção do planejamento antes do período de intervenção foram suprimidas à medida que as crianças se engajavam no conteúdo. A identificação das crianças com a produção visual do filme Kirikou: animais selvagens e a aproximação com suas vivências favoreceram o aprendizado.

\footnotetext{
7. Foram trabalhadas as seguintes brincadeiras: Mamba (África do Sul) - se assimila a um pique-pega, contudo as crianças pegas precisam correr com a mão no ombro do colega, simulando uma cobra; Banyoka (Zâmbia) - as crianças sentam em filas com os braços em volta do troco do colega da frente, sendo que o objetivo é se mover sem deixar que a corrente se quebre; Mbube Mbube (Gana) são nomeados um leão e uma empala, que devem jogar vendados dentro de um círculo delimitado pelos demais alunos, sendo que o leão deve tentar pegar a empala enquanto as crianças em roda emitem sons à medida que o leão se distancia ou aproxima da empala.
} 
Para a construção das práticas, foi necessário tensionar os saberes curriculares com as reivindicações de movimentos negros, o conhecimento externo ao currículo adquirido nos exercícios de pesquisa e leitura, além da participação em eventos acadêmicos da área onde foram debatidas a temática. Devido à dificuldade de encontrar propostas ou relatos de experiência no ensino da temática para crianças, foi feito um processo de ressignificação de práticas. Assim, brincadeiras comuns como pique-pega, "coelhinho sai da toca", caça ao tesouro, brincadeiras com massinha de modelar e de roda, dentre outros, foram ressignificadas e contextualizadas dentro da temática proposta.

Bem como em Pinto, Macamo e Azevedo (2014) e Macamo e Pinto (2016), intrínseco ao planejamento, foi construído um pano de fundo histórico para a construção das aulas que permite, nesta noção de historicidade, um reconhecimento do cotidiano atual enquanto um constructo histórico (PINTO; MACAMO; AZEVEDO, 2014; SOARES et al., 1992). Esta estruturação perpassou: a) a cultura em uma tribo no continente africano e a diversidade em África; b) a exportação dos personagens e violência; e c) a matriz africana em práticas cotidianas. Isso facilitou o andamento das aulas, uma vez que uma aula estava diretamente interligada à seguinte, permitindo transpor debates e reestruturar o planejamento.

É necessário situar que, nas três primeiras intervenções, houve grande dificuldade em lidar com a organização do espaço/tempo de aula, principalmente no que diz respeito a estruturação rígida das fases da aula. Ao início do estágio se concebia a Prática Social inicial, Problematização, Instrumentalização, Catarse e Prática Social final de forma rígida, no entanto, a partir da quarta intervenção, foi possível estabelecer um uso dinâmico destas fases, sem descaracterizar os pressupostos de Soares et al. (1992). A problematização foi diluída entre as atividades, permitindo um menor tempo de conversa inicial (que era produzida pelas crianças e mediada pelo professor), e as problematizações se davam a partir do contexto explorado em cada atividade, entrelaçando-se com a Prática Social inicial, expressada pelos alunos.

Nas três primeiras aulas, que se buscava uma construção para o exercício da docência, os trechos do filme, que geralmente eram utilizados durante 5-10 minutos ao início das intervenções, deram suporte ao aprendizado conceitual dos alunos, além de fundamentarem as problematizações e atribuírem significado às práticas. Mesmo com dificuldades, a avaliação diagnóstica que se fazia em todas as aulas demonstrava uma apropriação da temática por parte das crianças, tendo em vista que as mesmas demonstravam na prática social final um conhecimento superior ao apresentado inicialmente. Além disso, anotações feitas ao fim de cada aula demonstravam um envolvimento crescente das crianças com as atividades propostas.

Desse modo, uma proposta de tematização da cultura africana e afro-brasileira no ES, que a princípio produzia medo e insegurança, deu lugar à satisfação em ver que as crianças se sentiam parte da aula. Em seus relatos, foi gratificante perceber que reproduziram determinadas brincadeiras em casa ou foi assunto a ser compartilhado com os pais. Ademais, enquanto estagiário em formação, foi essencial perceber a pertinência dessa tematização naquele nível de ensino, estando a Educação Física a contribuir, desde os anos iniciais da Educação Básica com um conhecimento que, mesmo inserido no currículo por mando da lei, é pouco explorado e pode, ao ser tratado pedagogicamente, ser instrumento de resistências e de formação de sujeitos críticos, capazes de enfrentar os recorrentes preconceitos raciais presentes na sociedade.

\section{Considerações finais}

Considera-se que a parca divulgação de experiências diversas com temáticas africanas e afro-brasileiras na Educação Física e uma reduzida literatura deste tema específico na Educação Física, dificultou o trabalho de elaboração das práticas no ES. Soma-se a isso, o fato de que a formação em licenciatura em Educação Física na matriz cursada na Universidade não possibilitou formação para tal tematização no contexto escolar. Todavia, experiências externas ao currículo, ligadas aos debates étnico-raciais, puderam contribuir na elaboração de práticas que ajudaram a demarcar uma educação étnico-racial.

Na elaboração de uma proposta calcada na construção identitária do povo brasileiro, buscou-se criar um pano de fundo histórico nas aulas, onde elas estivessem interligas entre si. Este processo, amparado por um recurso audiovisual, permitiu a incorporação das crianças nas aulas, onde elas se sentiam atores 
da construção do conteúdo. Era perceptível que as crianças conseguiam conceber a existência do outro e de outra cultura, que influencia o cotidiano e as brincadeiras que elas usufruem, sendo que esses conhecimentos não se reduziam a aula, mas também era levado para fora da escola. No fim, um conteúdo que possuía uma grande complexidade interna por se tratar de outra cultura em um contexto de historicidade, demonstrou ter sido apropriado pelas crianças.

Portanto, é de suma importância reconhecer que a educação identitária também se constrói em um processo contínuo de reconhecimento do outro, que são as populações historicamente invisibilizadas, e identificação das suas contribuições. No caso deste relato do ensino com a Cultura Corporal Africana e Afro-Brasileira, por meio da disciplina de Estágio Supervisionado da Educação Física na Educação Infantil, foram adotados os pressupostos da Lei $n^{\circ} 10.639 / 03$ que estavam previstos apenas no Ensino Fundamental e Médio, de forma a contribuir para a percepção das crianças de práticas corporais cotidianas não-neutras e marcadas pelos saberes de matriz africana.

\section{Referências}

BRASIL. $L D B$ : lei de diretrizes e bases da educação nacional - lei n 9.394, de 20 de dezembro, que estabelece as diretrizes e bases da educação nacional. 14. ed. Brasília: Edições Câmara, 2017a. (Série legislação). Disponível em: http://bd.camara.gov.br/bd/bitstream/handle/bdcamara/19339/ldb_14ed.pdf. Acesso em: 18 jul. 2020.

BRASIL. Lei $\mathrm{n}^{\circ}$ 10.639, de 9 de janeiro de 2003. Altera a Lei $\mathrm{n}^{\circ}$ 9.394, de 20 de dezembro de 1996, que estabelece as diretrizes e bases da educação nacional, para incluir no currículo oficial da Rede de Ensino a obrigatoriedade da temática "História e Cultura Afro-Brasileira", e dá outras providências. Diário Oficial da União: seção 1, Brasília, DF, p. 1, 10 jan. 2003.

BRASIL. Ministério da Educação. Base Nacional Comum Curricular: educação é a base. Brasília, DF: MEC, $2017 \mathrm{~b}$. Disponível em: http://basenacionalcomum.mec.gov.br/images/BNCC_EI_EF_110518_versaofinal_site.pdf. Acesso em: 18 jul. 2020.

CENTRO MUNICIPAL DE EDUCAÇÃO DOUTOR JANUÁRIO DE ANDRADE FONTES (CMEDJAF). Projeto Político Pedagógico; escola de educação infantil e fundamental. Viçosa: PMV, 2017.

CLIMACO, Josiane Cristina; SANTOS, Márcia Lúcia dos; TAFFAREL, Celi Nelza Zulke. A Educação Física e a Lei 10.639/03: articulando com as matrizes africanas na escola em Salvador - BA. Revista da ABPN, Goiânia, v. 10, p. 676-692, maio 2018 .

KIRIKOU: os animais selvagens. Direção: Michel Ocelot e Bénédicte Galup. Produção: Didier Brunner, Marc Bonny, Michel Ocelot e Isabelle Peyrefitte. Roteiro: Bénédicte Galup, Michel Ocelot, Philippe Andrieux e Marie Locatelli. França: Europa Filmes, 2005. 1 DVD (74 min).

MACAMO, Arestides Joaquim; PINTO, Fábio Machado. Jogos e brincadeiras africanas e afro-brasileiras na educação física escolar: um relato de experiência. Cadernos de Estudos e Pesquisa na Educação Básica, Recife, v. 2, n. 1, p. 360-370, 2016.

PINTO, Fábio Machado; MACAMO, Arestides Joaquim; AZEVEDO, Naiade. Ensinando práticas corporais de origem afrobrasileira e africana na Educação Física escolar. Revista Brasileira de Ciências do Esporte, Florianópolis, v. 36, n. 2, p. 370-384, jun. 2014.

SAVIANI, Dermeval. Pedagogia histórico-crítica: primeiras aproximações. Campinas: Autores Associados, 1991. (Coleção Educação Contemporânea).

SOARES, Carmen Lúcia et al. Metodologia do ensino da educação física. São Paulo: Cortez, 1992.

TAFFAREL, Celi Zulke. Pedagogia histórico-critica e metodologia de ensino crítico-superadora da Educação Física: nexos e determinações. Nuances, Presidente Prudente, v. 27, n. 1, p. 5-23, jan./abr. 2016.

Data de submissão: 16/08/2020

Data de aceite: $07 / 10 / 2020$ 